\title{
Provenienz. Verdacht. Restitution.
}

\section{Die Suche nach NS-Raubgut in der Württembergischen Landesbibliothek Eine Kabinettausstellung}

In der Zeit des Nationalsozialismus wurden neben Kunstwerken auch massenhaft Bücher konfisziert oder zwangsveräußert. Oftmals waren die Besitzer gezwungen, ihre Bücher weit unter Wert zu verkaufen. Zahlreiche dieser Objekte wurden unmittelbar von staatlichen Autoritäten, die an der Beschlagnahmung beteiligt waren, an diverse Einrichtungen überwiesen oder sie sind über Umwege in den Besitz von Bibliotheken gelangt.

Die Ausstellung der Württembergischen Landesbibliothek informierte vom 16. April bis zum 22. Juni 2018 über Provenienzforschung in Bibliotheken und gab einen Einblick in das Projekt zur Suche nach NS-Raubgut, das seit Juni 2016 an unserer Landesbibliothek durchgeführt wird.

In fünf Großvitrinen wurden Bücher gezeigt, die im Verdacht stehen, aus NS-Raubgut zu stammen. Daneben wurden Hinweise auf die Vorbesitzer, aber auch auf Täterorganisationen, die am systematischen Bücherraub beteiligt waren und von ihm profitierten, erläutert. Dort, wo es die Forschungsergebnisse ermöglichen, wurden die Biographien der Vorbesitzer sowie die Umstände der Enteignung oder des Zwangsverkaufs rekonstruiert. Zahlreichen Buchexponaten konnten Fotografien der Vorbesitzer und ihrer Bibliotheken beigestellt werden. Die Verfolgung dieser Personen war ethnisch, religiös und politisch motiviert.

Die erste Vitrine war Privatpersonen gewidmet, die aus rassischen oder politischen Gründen vom NS-Regime verfolgt wurden. In den verdächtigen Büchern fanden sich Besitzspuren, die von mehreren Buchhändlern, Ehepaaren mit einem gemeinsamen Exlibris und Sammlern stammen. Geographisch lassen sich die Besitzeinträge auf Personen aus ganz Deutschland und auch aus dem Ausland zurückführen und beschränken sich nicht nur auf den württembergischen Raum. Eines der wenigen lokalen Beispiele aus Stuttgart sind die Funde zweier Bücher, die Klara Brettheimer gehörten. Sie wurde im Jahr 1944 gemeinsam mit ihrer Tochter deportiert und ermordet.

Neben dem Judentum und dem Marxismus galt die Freimaurerei dem Nationalsozialismus als weltanschaulicher Hauptgegner. Die Freimaurerlogen gehörten zu den ersten Institutionen, die vom NS-Regime aufgelöst und enteignet wurden. Als eindrückliches Beispiel hierfür dienten in einer weiteren Vitrine Bücher mit dem Besitzstempel der Loge "Johannes zum wiedererbauten Tempel" in Ludwigsburg, aus deren Besitz bereits knapp 100 Bände identifiziert werden konnten.

Die dritte Vitrine beleuchtete die Rolle der AuBenstelle der Hohen Schule in Stuttgart. Dieses „Institut für Biologie und Rassenlehre" wurde ca. 1941 gegründet und war gegen Kriegsende nach Schelklingen ausgelagert worden. Offensichtlich war der Aufbau einer eigenen Bibliothek schon recht weit fortgeschritten. Dabei hatte sich die Institution nachweislich an Raubgut bedient und dieses in ihre Bestände eingearbeitet. Die Bände gelangten nach Kriegsende in die Württembergische Landesbibliothek und wurden dort 1946 als Geschenk eingearbeitet.

Den Restitutionen war die vierte Vitrine gewidmet. In zwei Fällen ist es bereits gelungen, Erben geraubter Bücher ausfindig zu machen und Kontakt zu ihnen aufzunehmen. In beiden Fällen konnten gleich mehrere Bände den jeweiligen Vorbesitzern zugeordnet werden. Das jüdische Ehepaar Georg und Irma Baruch aus Hamburg muss eine typische bildungsbürgerliche Privatbibliothek besessen haben. In jedem der bisher 14 gefundenen Bände klebt das Exlibris des Ehepaars mit den Namen der Eheleute Baruch. Die Bücher weisen zudem eine zweite Provenienz auf, die zum Stuttgarter Apotheker Paul Braun führt. Er hat die Bände in den 1950er Jahren der Württembergischen Landesbibliothek geschenkt. 
Auch zu einem Erben des Frankfurter Mediziners Dr. Otto Rothschild konnte schon Kontakt hergestellt werden. Dessen Exlibris, das eine große Tanne zeigt, fand sich bisher in zwei Bänden. Der Entwurf des Exlibris stammte von dem italienischen Künstler Ettore Cosomati, mit dem die Familie Rothschild befreundet war.

Die letzte Vitrine zeigte offene Verdachtsfälle, deren Aufklärung zu den großen Herausforderungen der Forschung nach NS-Raubgut zählt. In der Masse der gefundenen Provenienzmerkmale sind die meisten nicht klar einer Person zuzuordnen. Immer wieder erregen jedoch Elemente in den Besitzkennzeichen die Vermutung, dass die Bücher von Personen stammen könnten, die vom NS-Staat verfolgt waren. Derartige verdächtige
Merkmale können zum Beispiel jüdische oder freimaurerische Symbole sein oder auch Signaturen mit Namensbestandteilen, die häufig in jüdischen Familien gebraucht wurden. Oft gleicht die Arbeit in der Provenienzforschung einer Detektivarbeit. Manchmal sind es aber auch Zufälle, die auf die richtige Spur führen.

Abgerundet wurde die Ausstellung durch 13 Führungen mit insgesamt 102 Personen.

\section{Kuratoren:}

Maria Nüchter und Dr. Hans-Christian Pust

Ausstellungsleitung:

Dr. Ida Danciu

Maria Nüchter / Hans-Christian Pust

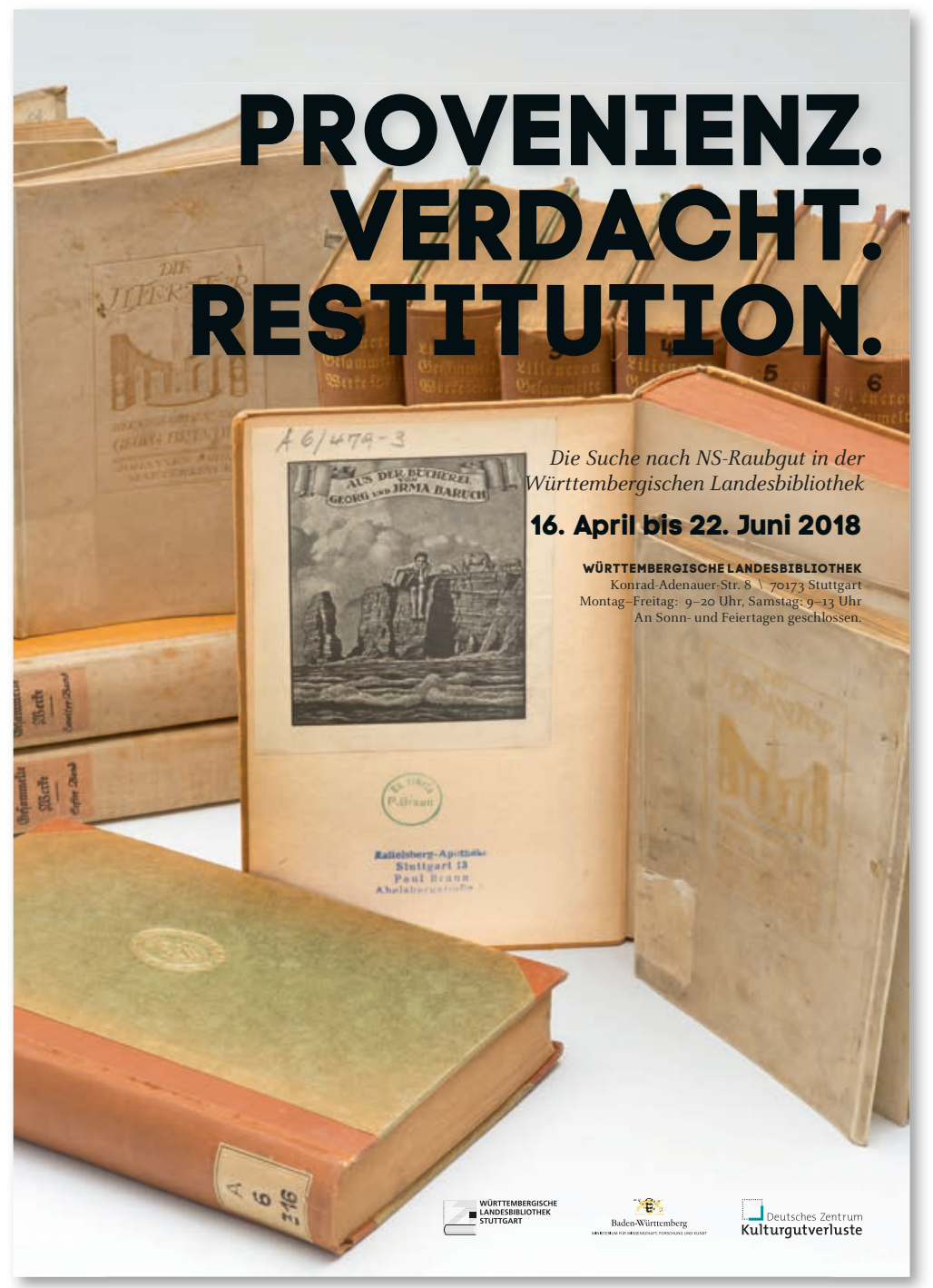

